\title{
REVISIÓN/REVIEW
}

\section{VIDEO MUSICAL Y CULTURA: PROPUESTAS PARA ANALIZAR EL CUERPO EN EL VIDEOCLIP}

Ana Sedeño-Valdellós': Universidad de Málaga. España. valdellos@uma.es

\section{RESUMEN}

El videoclip musical es un formato audiovisual que se encuentra en un espacio de conexión de numerosas disciplinas y en un lugar privilegiado para el análisis de la imagen y el sonido tal como son forjados desde una contemporaneidad cultural dominada por la imagen-exceso y la imagen-espectáculo. El trabajo asume que se pueden estudiar como textos culturales que representan ciertas tendencias sociales y culturales. En el texto se revisan formas de analizar el cuerpo desde la teoría cultural, filosófica, la teoría fílmica, repasando finalmente algunos estudios que se han acercado a la noción del "cuerpo" en el videoclip musical. Se emplean concepciones e ideas de Deleuze, Aumont, Foucault, Merlau-Ponty, Vernallis, Parodi u Oliveira.

PALABRAS CLAVE: Comunicación Audiovisual - Cinematografía - Antropología cultural - Análisis del discurso

\footnotetext{
${ }^{1}$ Autor correspondiente: Ana Sedeño-Valdellós: Profesora del Departamento de Comunicación Audiovisual y Publicidad de la Universidad de Málaga. España.

Correo: valdellos@uma.es
} 


\title{
MUSIC VIDEO AND CULTURE: PROPOSALS TO ANALYZE THE BODY IN VIDEO-CLIP
}

\begin{abstract}
Music video is a audiovisual format that is in a place of connection of many disciplines and in a privileged place for the analysis of image and sound in a visual culture dominated by excess-image and and show-image. The work assumes that music video can be studied as cultural texts that represent certain social and cultural trends. The text examines ways of analyzing the body from cultural theory, philosophy, film theory. Finally, the paper goes through some studies and approaches to the concept of "body" in the music video. Concepts and ideas are used by Deleuze, Aumont, Foucault, Merleau-Ponty, Vernallis, Parodi or Oliveira.
\end{abstract}

KEY WORDS: Audiovisual Media - Cinematography - Cultural anthropology Discourse analysis

\section{INTRODUCCIÓN}

\subsection{Posicionamiento del videoclip en la reflexión de la Teoría Social}

Como campo dependiente de la antropología social y cultural, la antropología visual trata de enfocar sus métodos a reflexionar sobre las formas en que el ser humano se relaciona con las imágenes. Lévy-Bruhl, en El alma primitiva (1927), clásico de esta disciplina, piensa las diferentes formas en que el ser humano entiende y vive las imágenes en contextos distintos. Desde entonces, algunos ensayos importantes han formado cuerpo teórico, como aquel grupo de estudios que se encarga de dilucidar los vínculos entre la visión y la mirada, así como en describir las formas de la mirada y las funciones de ésta en las sociedades. El ver como percepción y como construcción social dependiente de un cuerpo y de un estar en la realidad y la experiencia. Con frecuencia este tema se ha ligado a la investigación sobre cómo se construye el conocimiento antropológico a través de la mirada (y la audición en segundo término) y cómo se ha relegado a otros sentidos en esta empresa. Para Howes, el interés debía centrarse en "los modos de conocer, y el lugar del cuerpo en la mente" (Howes, 1991). Otros en la década de los noventa como Classen (1993), MacDougall (1998) u Okeley (1994) trabajaron este tema. Más recientemente se ha recuperado la experiencia multisensorial a través de la imagen en conexión con el cuerpo y los sentidos, en una aplicación de los presupuestos fenomenológicos de Merleau- Ponty con la aportación de Grimshaw y Ravetz (2005).

Según Elisenda Ardevol y Nora Montañola, en su libro Representación y cultura audiovisual en la sociedad contemporánea (2009), la antropología visual tiene como objetivo analizar la imagen como proceso cultural, entender la implicación de las imágenes en la construcción de la realidad social en la formación de identidades colectivas y los diferentes modos de representación en relación con las convenciones 
de género y tipos de sujeto receptor. Quien esto escribe pretende establecer una línea de reflexión en torno al cuerpo como categoría central en teoría social y antropológica (una de ellas) en la imagen contemporánea, empleando el videoclip musical como territorio de análisis. Como en los análisis de Geertz, nuestra pretensión sería realizar una descripción "densa" del videoclip, para descubrir su significación como artefacto cultural en constante interacción con sus agentes productores (televisión, productoras, estrategias promocionales de agentes y managers...) y sus audiencias, resaltando algunos mecanismos de conformación de identidades e imaginarios sociales y consolidación de poder cultural.

Sin duda, el videoclip musical puede servirnos para reflexionar sobre la construcción de algunos procesos culturales modernos. Este formato audiovisual parece insertarse en una determinada etapa del desarrollo industrial capitalista conocida en términos sociológicos y culturales como postmodernidad o postmodernismo, una condición o tipo de discurso filosófico y de análisis cultural interrelacionado con un marco completo de factores socioeconómicos en las sociedades occidentales de los años setenta y ochenta. Desde entonces, los procesos de mezcla e hibridación favorecen una revolución cultural, cuya confluencia en un sistema moderno de medios de comunicación fue descrita y criticada por el situacionismo y el letrismo a través de Guy Debord. Una nueva actitud social del arte reproduce cierta estructura de multiplicación existente en los bienes de consumo, en forma de exceso de signos. La televisión se conforma paradigma de medio masivo de circulación significante cuyos productos contienen altas dosis de ironía y procedimientos de intertextualidad (cita, parodia...). Desde entonces se ha producido una hibridación constante de técnicas de creación, producción y recepción artística:

Los textos híbridos en medios de comunicación reflejan la existencia de una variedad de fuerzas históricas, culturales y económicas que se mezclan entre sí y que son visibles tanto como manifiesto a nivel local, nacional y regional, como globalmente. Centrarse únicamente en el medio no es suficiente para comprender estas relaciones complejas. En lugar de esto, necesitamos situar el medio en su entorno social y disociar los diversos procesos enlazados y efectos posibles entre las prácticas de comunicación y las fuerzas sociales, políticas y económicas. (Kraidy, 2005, p. 6).

A esta intertextualidad e hibridación debe unirse una estética de la fragmentariedad, para terminar de describir los fenómenos artísticos posmodernos. Las continuas referencias, citas, homenajes que ejercen entre sí los textos culturales no sólo cambian la obra que se suma a las anteriores, sino que transforma la forma de entender toda la historia del arte, en un proceso retroalimentador "sin fin" de modificación de las condiciones de recepción de las mismas.

Esta multiplicidad de normas estilísticas medios, artes, tendencias y épocas define una especie de eclecticismo sincrónico y diacrónico que actúa como oposición de la exclusividad de lo moderno. La posmodernidad supone una negación de los valores 
modernos en que actuaban ciertos opuestos que hacían estable la experiencia y el conocimiento del mundo (realidad/ficción, alta cultura/cultura popular...).

El videoclip musical, un formato audiovisual propiamente concebido y desarrollado desde las instancias de la industria, ha heredado unas fórmulas discursivas (estética, puesta en escena, realización) recibidas desde sus antecedentes comunicacionales y culturales (vídeo de creación, bellas artes, medio cinematográfico), así como de su naturaleza de formato inserto en un universo comunicacional electrónico, cuya tecnología condiciona los modos de captación, registro y postproducción de la imagen y, en parte, sus lógicas de producción.

El videoclip ha bebido de todas las vanguardias artísticas, de su lenguaje y sus objetivos, y debe mucho al procedimiento del collage, junto con procedimientos del cubismo en su discurso fragmentario y su multiperspectivismo, que tiene incluso implicaciones en su lógica productiva, pues contiene una amalgama de posicionamientos variados respecto a la dicotomía alta cultura/cultura popular.

El comunicólogo mexicano Néstor García-Canclini en su texto Culturas híbridas habla del proceso de hibridación cultural contemporáneo y pone al clip como ejemplo paradigmático de ruptura de los conjuntos fijos, de bienes simbólicos, anteriormente reconocidos como grupos diferenciados y jerarquizados, con el consiguiente aumento en la dificultad de diferenciar entre lo culto, lo popular y lo masivo. Este formato llega a erigirse como una excepcional herramienta de teorización sobre el imaginario de la vida contemporánea para los estudios socioculturales, como cuando este autor establece paralelismos con las formas de habitabilidad real y simbólica en las grandes urbes latinoamericanas. Con esta metáfora trata de explicar la formación de las megalópolis contemporáneas, donde las identidades se suman, como las partes de una ciudad, fagocitando los "miembros" anteriores, "incorporándose" unos a otros en un proceso sin fin. Néstor García-Canclini habla de la ciudad videoclip:

La primera es la ciudad histórico-territorial. (...). La segunda ciudad que descubrimos es la ciudad industrial. (...) (La tercera ciudad aparece) cuando los economistas y los urbanistas advirtieron que la industrialización ya no era el agente económico más dinámico en el desarrollo de las ciudades, se empezaron a considerar otros impulsos para el desarrollo que son básicamente informacionales y financieros... (...) (de la coexistencia de estas tres ciudades surge) la ciudad videoclip, esta ciudad que hace coexistir en ritmo acelerado un montaje efervescente de culturas de distintas épocas. No es fácil entender cómo se articulan en estas grandes ciudades esos modos diversos de vida, pero más aun los múltiples imaginarios urbanos que generan. No sólo hacemos la experiencia física de la ciudad, no sólo la recorremos, y sentimos en nuestros cuerpos lo que significa caminar tanto tiempo o ir parado en el ómnibus, o estar bajo la lluvia hasta que logramos un taxi, sino que imaginamos mientras viajes, construimos suposiciones sobre lo que vemos, sobre quienes nos cruzan, las zonas de la ciudad que desconocemos que tenemos que atravesar para llegar a otro destino, en suma, qué asa con los otros en la ciudad... toda interacción 
tiene una cuota de imaginario, pero más aún en estas interacciones evasivas y fugaces que propone una megalópolis (García-Canclini, 1997, pp. 80-89).

Todo ello tiene algunos resultados en la aparición de un nuevo espectador: la recepción y decodificación de los textos por el sujeto postmoderno se caracteriza por una continua búsqueda de referencias a textos anteriores para conseguir un consumo placentero una recepción significativa.

\section{EL CUERPO EN LA FILOSOFÍA Y LA TEORÍA FÍLMICA}

La El cuerpo como material, lenguaje y tema de la creación contemporánea viene precedido de una teoría social, después del estructuralismo y las posturas sistémicas, que lo percibió antes como problema, desde el que afrontar las preguntas eternas en torno al ser humano y lo social. La antropología ha dado cuenta de este vínculo. Geertz, por ejemplo, se ha ocupado de rescatar la relación entre la vida social y la emergencia de expresiones artísticas:

La capacidad [...] para percibir el significado de las pinturas (o de poemas, melodías, edificios, cerámicas, dramas y estatuas) es, como todas las restantes capacidades humanas, un producto de la experiencia colectiva que la trasciende ampliamente, y donde lo verdaderamente extraño sería concebirla como si fuese previa a esa experiencia. A partir de la participación en el sistema general de las formas simbólicas que llamamos cultura es posible la participación en el sistema particular que llamamos arte, el cual no es de hecho sino un sector de ésta (Geertz, 1994, p. 133).

El cuerpo porta un ser social y la historia de la representación humana ha sido, de alguna manera la de la representación del cuerpo.

En todos los ámbitos de la vida social, el cuerpo ha resultado el objeto y "el centro de muchas preocupaciones tecnológicas e ideológicas. En la producción, en el consumo, en el ocio, en los espectáculos, en la publicidad, etc., el cuerpo se ha convertido en un objeto de tratamiento, de manipulación de mise-e-scene, de mercadeo. Es sobre el cuerpo donde convergen toda una retahíla de intereses sociales y políticos en la actual "civilización tecnológica". (Brohm, cit. en Bernard, 1976, p. 13)

Han sido varios los intentos, particulares como los de Hans Belting (antropología) y Foucault (análisis del discurso), así como de ciencias completas (semiótica), por encontrar una metodología híbrida en relación al cuerpo. El cuerpo del actor, interpretante o ser humano en la pantalla se ha convertido en una unidad básica del lenguaje de la imagen en movimiento, para directores como John Cassavettes o Pier Paolo Pasolini. Tanto Serge Daney (2004) como Iain Chambers (1995) han teorizado sobre cómo la imagen tiene la capacidad de plantear la complejidad del mundo actual por su evocación de nuevas formas de alteridad. En este sentido, quizás sea la 
fenomenología la que, desde un enfoque filosófico, ha logrado establecer modos de concebir la relación entre la experiencia y el ser contemporáneo:

El cuerpo es nuestro medio general para tener un mundo. Por momentos se limita a las acciones necesarias para preservar la vida y, en consecuencia, pone a nuestro alrededor un mundo biológico, a veces jugando con sus primeros gestos y pasando de su sentir propio a un sentido figurado, se manifiesta a través de ellos un nuevo núcleo de significación: es el caso de los hábitos motores de la danza. Ahora, por fin la significación alcanzada no se puede lograr por medios naturales del cuerpo, entonces es necesario construir un instrumento, y se proyecta en torno a un mundo cultural (Merleau-Ponty, 1994, p. 203).

Respecto a la teoría audiovisual y fílmica, podemos reconocer un primer estadio en el pensamiento sobre el cuerpo en los teóricos cinematográficos de los primeros años del siglo XX. Tras una representación de tendencia levemente documental en el cine primigenio (en los que parecía entenderse el cuerpo en su relación con la organización política de lo laboral, es decir, como cuerpo productivo), pronto se desvia este perfil hacia una cierta inmovilidad en la figura de la diva, el cine musical o el vaudeville. Desde un mismo ángulo de visión del cuerpo como organismo, en su glorificación como máquina de buen funcionamiento, algunas vanguardias (futurismo, constructivismo), y sobre todo, el cine documental de Leni Riefenstahl (de encargada producción por el régimen nazi), siguieron la senda corta de sublimación abstracta del cuerpo orgánico, culmen de conceptos como belleza, fuerza o armonía, claves, por otro lado, de mucha de la concepción clásica del arte.

Tras esto, hay que destacar la aparición del primer plano como un nuevo paso en el pensamiento sobre el cuerpo en la imagen. Como han descrito Jacques Aumont (1998) y Gilles Deleuze (1987), el concepto del primer plano nace cuando es utilizado en su función específica (ya en el cine primitivo se empleaba pero no con su potencial de liberación de la expresión) y el cuerpo completo se transforma por su efecto. El primer plano deviene en un medio para exponer los afectos, como apuntaba agudamente Spinoza (1984, p. 169): "Por afectos entiendo las afecciones del cuerpo, por las cuales aumenta o disminuye, es favorecida o perjudicada, la potencia de obrar de ese mismo cuerpo, y entiendo al mismo tiempo, las ideas de esas afecciones".

Ricardo Parodi (2004) ha estudiado cómo el cine de Carl Theodor Dreyer y de Robert Bresson aprovechan al límite las capacidades del primer plano para encarnar los afectos en películas como La pasión de Juana de Arco (Carl T. Dreyer, 1928) o Pickpocket (Robert Bresson, 1959).

El gestus de Deleuze y Guattari (1988) supone un nuevo paso en la descripción del desmenuzamiento en partes, en fragmentos, del cuerpo, en la cultura audiovisual contemporánea. Si bien entendido desde un punto de vista individual, supone una importante herramienta teórica para describir películas en el naciente cine moderno (como Deleuze lo llama, la imagen-movimiento), es en su carácter colectivo donde el 
concepto nos resulta más fructífero, complejo y enriquecedor en la reflexión sobre el cuerpo contemporáneo, el germen del rito y la ceremonia.

En The cinematic body, Steven Shaviro describe el aparato cinemático como un "nuevo modo de corporeidad" y Lisa Cartwright, en Screening the body, siguiendo el esquema de cuerpo social de Michel Foucault, traza otro vínculo, esta vez entre el cine y la historia del análisis y de la vigilancia del cuerpo en la medicina y la ciencia (Cartwright, 1995).

\section{EL CUERPO EN CONTINUA MUTACIÓN DEL VIDEOCLIP}

La teoría cultural ha ensayado algunos análisis desde la posición del videoclip como formato a medio camino entre la publicidad y la música popular: en el caso de Juan Alberto Leguizamón (2001) declama la movilización que el clip impone sobre el cuerpo, aspecto que recoge como dispositivo de mediación de la música popular.

Simon Frith desenmascara alguna de las estrategias de las industrias culturales para establecer criterios de gusto y placer visual. En Music for pleasure, por ejemplo, afirma explícitamente que "las discográficas computan el éxito de los videoclips en función de los procesos de creación de una estrella, no en cuanto a la venta de singles" (Frith, 1988, p. 215). La fragmentación de la realización y el primer plano se convierten en técnicas clave para centrar la atención del espectador en el cuerpo del artista/cantante, desrealizándolo y alejándolo del clasicismo visual y del modo de representación institucional (MRI, según terminología de Noël Burch).

No se trata de verificar sólo en el nivel narrativo la presencia de la organizacidad. Se trata de comprobar que dicha organizacidad se apoya ante todo, desde el comienzo mismo de su historia, incluso antes de que el cine primitivo alcanzara esa "Gran Forma Narrativa" que define el centro de operaciones del cine institucional, en una organización del cuerpo dese dond ese destilan y otorgan sentido a las posteriores particiones significantes del film y a los conceptos de individuo, identidad y yo (Parodi, 2004, p. 81).

El fragmento del cuerpo en los videoclips de tipo performance en forma de detalle o primer plano supone una desjerarquización y exaltación de sus mínimas partes, y una "redistribución de la intensidad" (Parodi, 2004, p. 81) y, por tanto, una pérdida de la organicidad del cuerpo.

Este mecanismo de desmembramiento puesto en marcha en el videoclip puede entenderse como una estrategia de representación sensorial que recoge este formato desde la música popular. La escucha de los artistas favoritos en vivo era una condición esencial del incipiente rock and roll, provocando altos niveles de exaltación y apasionamiento en el público joven. Desde los inicios de este tipo de música, la actuación en vivo y el concierto saciaron la necesidad de ese contacto físico a la que invitan, en su mayoría, ciertos géneros y derivaciones de música contemporánea. Con la llegada generalizada de la televisión se instituyó un nuevo modo de escucha a 
distancia: la actuación grabada de un concierto y a continuación la realizada en un plató televisivo, normalmente en playback. Estas representaciones son el germen del clip, nacido precisamente cuando las discográficas avistaron la versatilidad e inmediatez del medio videográfico y todas sus posibilidades en posproducción, ya ensayadas en prácticas de videoarte: se lograba el enriquecimiento de la puesta en escena en plató a través del tratamiento retórico de la imagen. Esta fue la manera de atenuar esa distancia creciente entre el artista y su público: lo que se perdía de la fisicidad y presencia del concierto se compensaba con la adición de altas dosis de personalidad y una creciente intensidad representativa gracias a los códigos de connotación de la imagen (iluminación, planificación, edición...), una más alta fragmentación visual y la preferencia por planos cortos (primeros planos y detalles). El cuerpo fragmentado y en detalle perpetuo, adornado con movimientos de seguimiento y zoom retoma el placer de la vivencia del concierto en directo para darle una nueva forma con técnicas de fruición escópica.

Desde el análisis del discurso se ha asistido a algunas exploraciones interesantes en esta dirección. El videoclip puede entenderse como "maquinaria ideológica" (Vernallis, 1998, p. 153) que construye socialmente a los individuos: el cuerpo de los cantantes y músicos, su look conforma formas de visualidad permitidas y diferentes grados de aceptación y éxito social. En Aesthetics of Music Video de Carol Vernallis (1998) trata de realizar un trabajo sobre la construcción del cuerpo y la representación de la imagen de los cantantes y músicos en el videoclip. La autora asume que en el análisis individual de ciertos videoclips se pueden generalizar formas de elaborar la representación de categorías como sexualidad, género y raza.

También Robert Walser (1993) ha estudiado los aspectos que configuran fórmulas icónicas tipificadoras en el videoclip según su género musical en Running with the devil. Power, gender, and madness in heavy metal music, donde trata especialmente este estilo.

Por su lado, Taize Oliveira (2009) despliega un interesante análisis sobre videoclips como Smack my bitch up, Dirrty, Dani California o The Weekend empleando el concepto de cuerpo dócil y cuerpo performativo de Michel Foucault (1996) y Judith Butler (2002), respectivamente. La capacidad para exhibir y legitimar sobrepasa la materialización del objeto musical a través del cuerpo de su productor, el cantante/artista/músico y permite hablar de cuerpo-Cyborg (un paso más en la creación de formas de identidad desmembrada, desmontable y remontable, que puede disfrutarse en algunos videoclips de Marilyn Manson), el cuerpo monstruoso (a la manera de David Lynch o Michael Haneke en las obras de Chris Cunningham) y el cuerpo-música en los producidos para Björk por Michel Gondry o el mismo Cunningham.

En todos ellos, podemos asistir a un cuerpo que, en el videoclip (lejos de los condicionantes de la narratividad del discurso fílmico clásico) se entrega a la tecnología como manera de hibridarse y complejizar su identidad. Podría hablarse de una nueva tecnología del yo (Foucault, 1996). 


\section{CONCLUSIONES}

Parece quedar claro que el videoclip musical podría convertirse en un nuevo territorio de análisis del cuerpo en los textos culturales contemporáneos, como ya lo han sido los fílmicos. La tradición y cierta jerarquia cultural a favor cinematográfico ha condicionado un más alto grado de reflexión en torno a esta perspectiva, lo que no significa que otros formatos carezcan de similar potencial. En el caso del videoclip, existen además implicaciones que tienen que ver con el estudio de las nuevas identidades posibles en la mutable relación entre productores/realizadores y receptores. Categorías clásicas como las de autor, ya problematizadas desde el postestructuralismo por algunos autores citados como Deleuze, Guattari, oFoucault, acaban por descomponerse. La asunción clásica de que en el estudio de las imágenes existe "una mirada sobre lo real que no se mezcla con lo real" (Augé, 1998, p. 150) segregando así, incluso físicamente, la creación o autoría de las imágenes de su recepción y fruición- va quedando atrás. Este paradigma se reinventa en el medio vídeo, en el que las imágenes pueden ser reinterpretadas infinitamente para gestionar modos múltiples de identidad y establecer nuevos límites a nociones como imagen, lugar y presencia. Las posibilidades de creación de versiones de videoclips oficiales (los producidos por las casas discográficas) a través de los AMV (anime music videos) y los UMV (user's music video) dan al espectador-fan una capacidad de producir lo que podríamos llamar videoclips personalizados.

Esta es sólo una de las perspectivas desde las que sería enriquecedor acometer análisis complejos de corpus de videoclips respecto a la creación de la identidad de fans, receptores y prosumers activos de estos formatos personalizados. A pesar de su centralidad para tratar algunas problemáticas contemporáneas como las de la identidad, la mirada o la representación, el videoclip musical es uno de los formatos más desconocidos y escasamente enfrentados desde la teoría social y antropológica. Con este texto se ha tratado de atenuar esta tendencia.

\section{REFERENCIAS}

Augé, M. (1998). La guerra de los sueños: ejercicios de etno-ficción. Barcelona: Gedisa.

Ardevol, E. \& Nontañola, N. (2009). Representación y cultural visual en la sociedad contemporánea. Barcelona: UOC.

Aumont, J. (1998). El rostro en el cine. Barcelona. Paidós.

Bernard, M. (1976). El cuerpo. Barcelona: Paidós.

Butler, J (2002). Cuerpos que importan. Sobre los limites materiales y discursivos del "sexo". Buenos Aires: Paidós. 
Comunicación Audiovisual - Cinematografía - Antropología cultural - Análisis del discurso

Belting, H. (2002). Antropología de la imagen. Madrid: Katz.

Cartwright, L. (1995). Screening the Body: Tracing Medicine's Visual Culture. Minneapolis and London: University of Minnesota Press.

Chambers, I. (1995). Migración, cultura e identidad, Buenos Aires.

Daney, S. (2004). Cine, arte del presente. Buenos Aires.

Deleuze, G. (1987). La imagen tiempo. Estudios sobre cine II. Barcelona: Paidós.

Deleuze, G. y Guattari, F. (1988). Mil mesetas, capitalismo y esquizofrenia. Valencia: pretextos.

Foucault, M. (1996). Tecnologías del yo y otros textos afines. Barcelona: Ediciones Paidós Ibérica.

Frith, S. (1988). Music for pleasure. New York: Routledge.

García Canclini, N. (1990). Culturas híbridas: Estrategias para entrar y salir de la modernidad. México D.F.: Grijalbo.

Geertz, C. (1987). La interpretación de las culturas. Barcelona: Gedisa.

Grimshaw, A. Et alter (2005). Visualizing anthropology. Bristol: Intellect Books.

Kraidy, M. (2005). Hibridity or the cultural logic of globalization. Philadelphia: Temple University Press.

Leguizamón, J. A. (2003). El videoclip como formato o género h. Recuperado el 29 de junio de 2011 en http:/ / www.fortunecity.co/victorian/bacon/1244/Leguiz.html.

Lévi-Bruhl, L. (1985). El alma primitiva. Barcelona: Ediciones Península.

MacDougall, D. (1998). Transcultural Cinema. Princeton, New Jersey: Princeton University Press.

Merleau-Ponty, M. (1994). Fenomenología de la percepción. Barcelona: Península. 
Oliveira de Araujo, T. (2009). Videoclip y cuerpo. El entre-lugar de los cuerpos mutantes. Trabajo de investigación para Programa de Doctorado en Teoría de la literatura y Literatura comparada de La Universidad Autónoma de Barcelona, Barcelona, España.

Parodi, R. (2004). "Cuerpo y cine. Reporte fragmentario sobre extrañas intensidades y mutaciones del orden corporal", en G. Yoel, Pensar el cine 2: cuerpo (s), temporalidad y nuevas tecnología (pp.73-100). Buenos Aires: Manantial.

Pérez Yarza, M. (1996). Videoclip e imágenes del descrédito: Black Hole Sun, de Soundgarden. Valencia: Episteme. Colección Eutopías (Documentos de Trabajo), Vol. 129.

Shaviro, S. (1993). The cinematic body. Minnessota: University of Minnesota Press.

Spinoza, B (1984): Ética demostrada según el orden gemométrico. Buenos Aires: Hispamérica.

Vernallis, C. (2004). Experiencing Music Video. Aesthetics and cultural context. New York: Columbia University Press,.

Vernallis, C. (1998). The Aesthetics of Music video: Analysis of Madonna's Cherish. Popular music, vol. 17/2: 153-186.

Walser, R. (1993). Running with the deil: Poser, gender and madness in heavy metal music. Hanover: Wesleyan University Press.

\section{Ana Sedeño Valdellós}

Doctora en Comunicación Audiovisual desde 2003 y Profesora Contratado Doctor en el Departamento de Comunicación Audiovisual y Publicidad. Sus campos de investigación se relacionan con el papel de la música en formatos audiovisuales como el videoclip, así como con la historia del arte cinematográfico y los nuevas manifestaciones audiovisuales como el live cinema o el mapping. Ha publicado libros como El lenguaje del videoclip (2002) o Comunicación y Música I: Lenguaje y medios y Comunicación y música II: Tecnología y audiencias (2008) (UOC Press). 